\title{
Leiomyoma: a common benign tumor at an unusual location
}

\author{
N.V. Manjula, ${ }^{1}$ Jyothi G.S. ${ }^{1}$ \\ Keywords: Vaginal leiomyoma, leiomyoma, benign vaginal tumors, anterior vaginal wall tumor
}

\begin{abstract}
Leiomyoma in the female genital tract is a common benign tumor of the uterus, followed by cervix, round ligament and inguinal ligament. Vaginal leiomyoma is a rare entity with only about 300 reported cases. ${ }^{1}$ Here, we report a case of a vaginal leiomyoma in a 22 year old nullipara who presented with dyspareunia and infertility. Vaginal examination revealed a mass in the anterior vaginal wall. MRI of the pelvis revealed a hypoechogenic and hypointense mass in the anterior vaginal wall. Excision of the tumor was done by the vaginal route. Histopathology revealed a benign leiomyoma.
\end{abstract}

${ }^{1}$ MS Ramaiah Medical College, Bangalore, India

\section{Introduction}

Vaginal leiomyomas remain an uncommon entity with only 300 reported cases. ${ }^{1}$ Other uncommon vaginal tumors are papilloma, hemangioma, and mucosal polyps. Vaginal fibroids rarely exist as a primary tumor of the vagina. These tumors are benign, solitary, smooth muscle neoplasms, and when large in size, symptoms may include vaginal discharge or bleeding, dyspareunia and urinary retention. The differential diagnosis of anterior vaginal tumors includes urethral diverticulum, fibroepithelial polyp, cystocele, Skene duct abscess or vaginal malignancy. ${ }^{2}$ We report a case of a vaginal leiomyoma in a nullipara.

\section{Case Report}

A 22 year old nullipara presented with dyspareunia and infertility for 3 years. Her cycles were regular, with moderate flow and dysmenorrhea. General and systemic examinations were normal. Vaginal examination revealed a mass measuring about $6 \mathrm{~cm} \times 6 \mathrm{~cm}$ in the anterior vaginal wall, $2 \mathrm{~cm}$ below the urethral meatus. On speculum examination, the cervix was pushed posteriorly. The tumor was firm in consistency and felt separately from the cervix and the uterus and no nodularity was felt in the pouch of douglas (Figure $1)$.

Please cite this paper as: Manjula NV, Jyothi GS. Leiomyoma: a common benign tumor at an unusual location. Proceedings in Obstetrics and Gynecology, 2015;5(1):Article 5 [ 4 p.]. Available from: http://ir.uiowa.edu/pol/. Free full text article.

Corresponding author: N V Manjula, MS Ramaiah Medical College, Bangalore, India, manjulanv_kv@yahoo.co.in

Financial Disclosure: The authors report no conflict of interest.

Received: 17 June 2015; received in revised form: 1 July 2015; accepted 29 July 2015

Copyright: (c) 2015 Manjula et al. This is an open-access article distributed under the terms of the Creative Commons Attribution License, which permits unrestricted use, distribution, and reproduction in any medium, provided the original author and source are credited. 


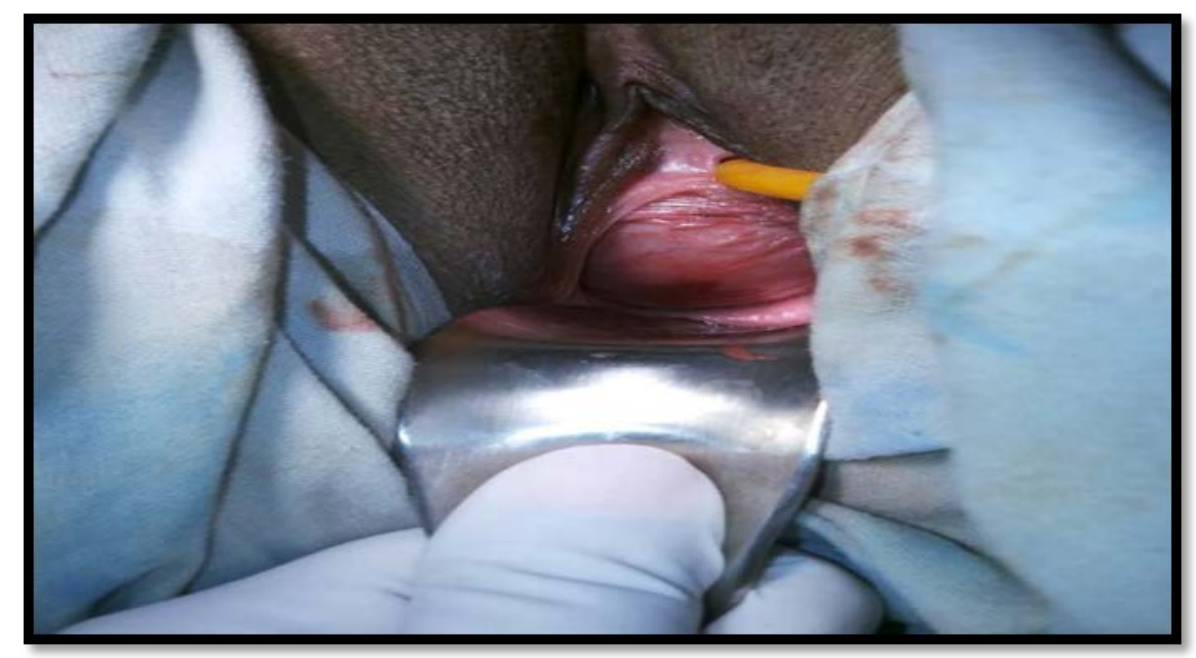

Figure 1. Mass in the anterior vaginal wall

MRI revealed a large $T 2$ heterogeneous predominantly hypo intense mass (62 $\mathrm{mm} \times 52 \mathrm{~mm} \times 58 \mathrm{~mm}$ ) in the vesicovaginal location with homogenous contrast enhancement (Figure 2).

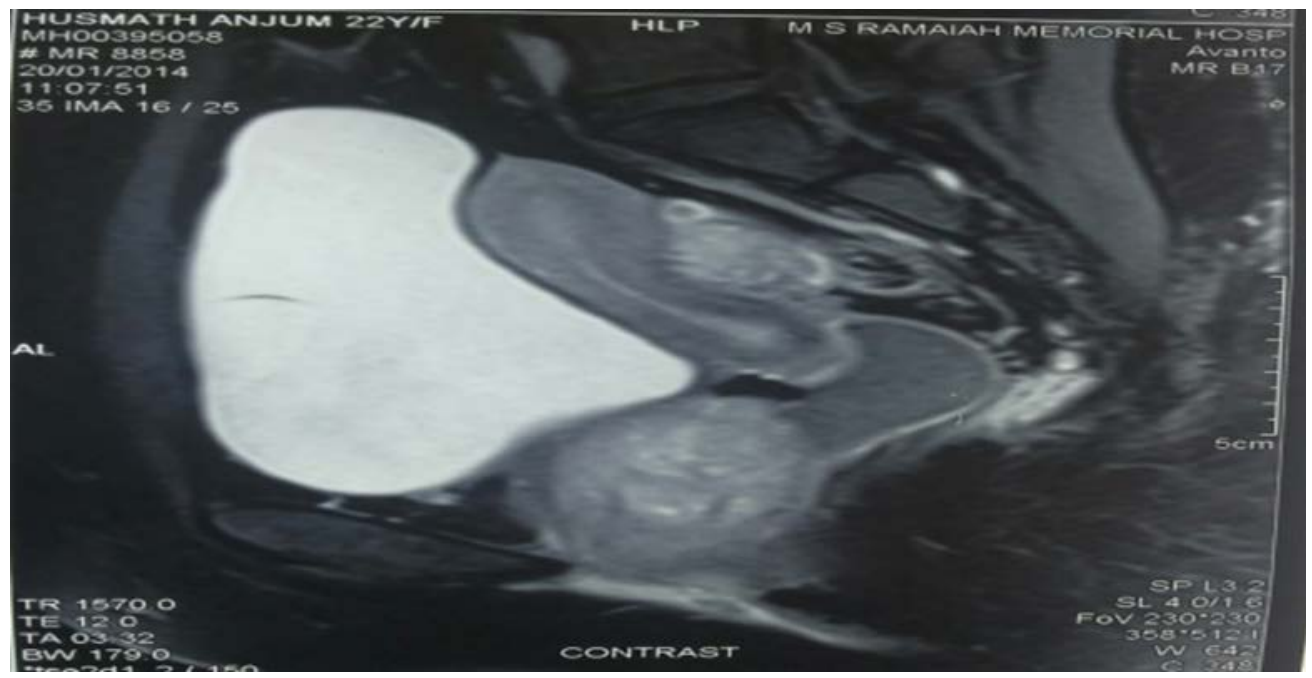

Figure 2. T2 Image of a heterogenous mass in the vesicovaginal location

The patient underwent laparoscopy with the following findings: both tubes were patent, the ovaries were polycystic and the uterus appeared normal. The bladder was catheterized with Foley's and the tumor was excised by the vaginal route. With a $3 \mathrm{~cm}$ vertical incision on the anterior vaginal wall one 
centimeter below the external urethra meatus the tumor was enucleated by blunt dissection. The tumor was firm in consistency, well capsulated, measuring
$8 \mathrm{~cm} \times 7 \mathrm{~cm} \times 4 \mathrm{~cm}$ and weighing 80 grams (Figure 3). Histopathology revealed leiomyoma.

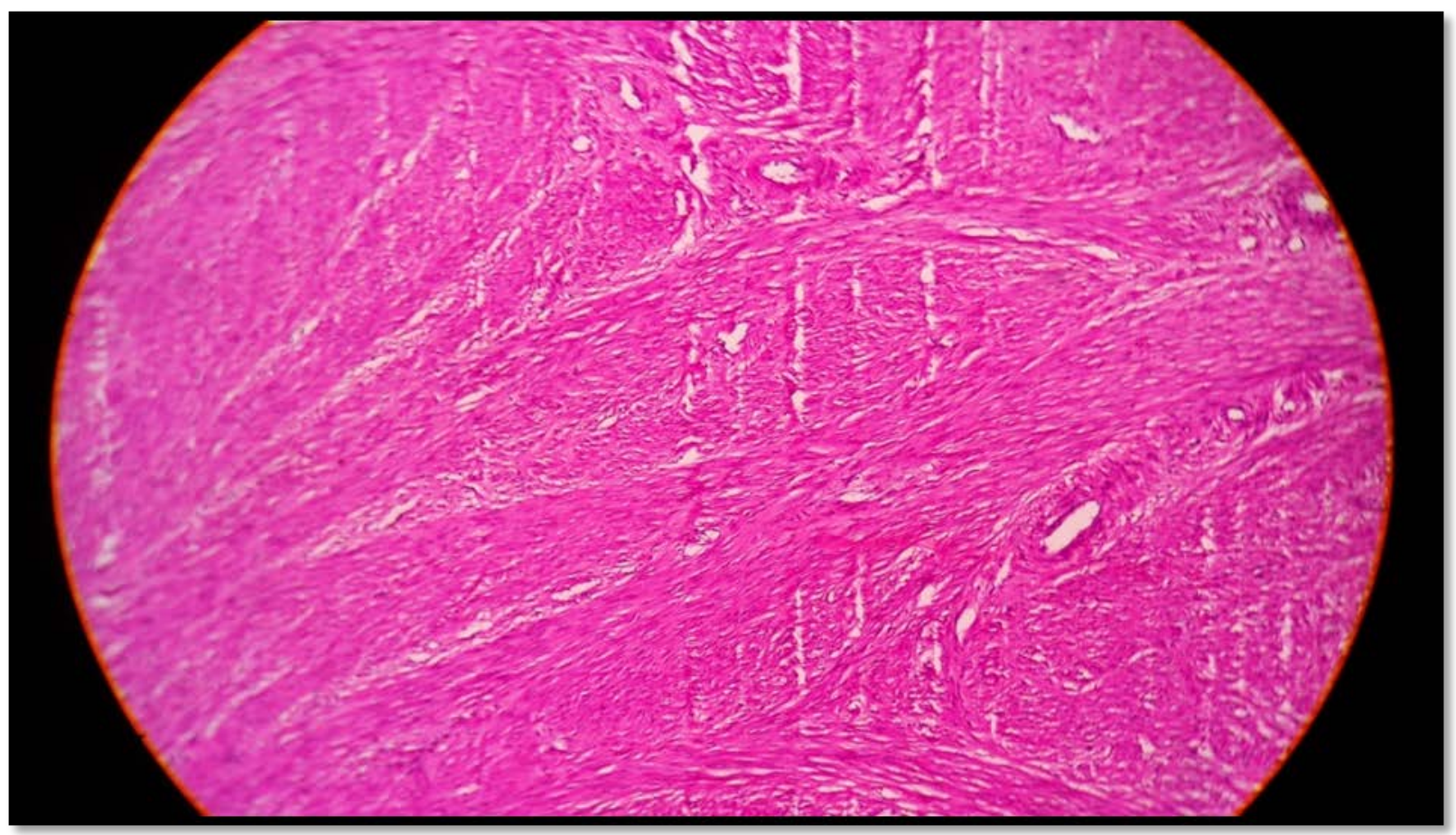

Figure 3. Histopathology showing spindle cells with whorled appearance

\section{Discussion}

The incidence of vaginal leiomyoma is very rare with only around 300 cases reported. It was first described in 1733 by Denys de Leyden., ${ }^{1,2}$ Uterine leiomyoma are benign tumors of the myometrium, although uncommon, loci have also been described in the urinary bladder, round ligament and broad ligament. ${ }^{3}$ In the vagina, they present primarily through the anterior wall and secondarily through the lateral walls. ${ }^{4}$ They may arise from the posterior wall even after hysterectomy in the form of ischiorectal abscess. Initially, vaginal leiomyoma may be asymptomatic. With the growth of the tumor, compression occurs which may precipitate symptoms. ${ }^{5}$ Leron et. al. reported symptoms of prolapse with urinary urgency and urge incontinence. ${ }^{6}$ In our case, the subject presented with dyspareunia and no compressive symptoms. Urethral leiomyoma has also been reported presenting with pain and swelling in the urethra and difficulty in micturition. ${ }^{7}$

Preoperative diagnosis by ultrasound 
may be difficult, but MRI clinches the diagnosis. ${ }^{8,9}$ Surgical excision by the vaginal route, with urethral catheterization to protect the urethra from injuries, is the treatment of choice.$^{10}$ Follow up is important because while uncommon recurrence has been reported. ${ }^{11}$

\section{Conclusion}

Vaginal leiomyoma are rare in compared to uterine leiomyoma. Vaginal leiomyoma should be the differential diagnosis in anterior wall tumors with follow up to monitor for recurrence of the tumor.

\section{References}

1. Young SB, Rose PG, Reuter KL. Vaginal fibromyomata: two cases with preoperative assessment, resection, and reconstruction. Obstet Gynecol. 1991 Nov;78(5 Pt 2):972-4. PubMed PMID: 1923243.

2. Liu MM. Fibromyoma of the vagina. Eur J Obstet Gynecol Reprod Biol. 1988 Dec;29(4):321-8. http://dx.doi.org/10.1016/00282243(88)90073-1 PubMed PMID: 3229545 .

3. Bennett HG, Jr. Ehrlich MM. Myoma of the Vagina. Am J Obstet Gynecol. 1941;42:314-20.

4. Elsayes KM, Narra VR, Dillman JR, Velcheti V, Hameed $\mathrm{O}$, Tongdee R, Menias CO. Vaginal masses: magnetic resonance imaging features with pathologic correlation. Acta Radiol. 2007 Oct;48(8):921-33. doi: 10.1080/02841850701552926 PubMed PMID: 17924224.
5. Gupta V, Arya P, Gupta V, Rawat DS. A rare case of vaginal fibroid presenting as ovarian tumor. J Obstet Gynecol India. 2006 Nov/Dec; 56(6):537-8.

6. Leron E, Stanton SL. Vaginal leiomyoma--an imitator of prolapse. Int Urogynecol J Pelvic Floor Dysfunct. 2000 Jun;11(3):196-8. doi: 10.1007/s001920070048 PubMed PMID: 11484748.

7. Senthil Kumar S, Gowri Sankar R, Viswanathan P, Tippoo R, Ali . Urethral leiomyoma - a very rare entity. Journal of Evolution of Medical and Dental Sciences 2013 Nov 25;2(47):9077-9080.

8. Bae JH, Choi SK, Kim JW. Vaginal leiomyoma: a case report and review of literature. J Women's Med. 2008 Dec;1(2):92-4.

9. Shadbolt CL, Coakley FV, Qayyum A, Donat SM. MRI of vaginal leiomyomas. J Comput Assist Tomogr. 2001 MayJun;25(3):355-7.

http://dx.doi.org/10.1097/00004728200105000-00005 PubMed PMID: 11351183.

10. Tramier D, Marinetti C, Jouve MP. [Leiomyoma of the vagina: a report on 2 cases (author's transl)]. J Gynecol Obstet Biol Reprod (Paris). 1980;9(3):367-8. French. PubMed PMID: 7462563.

11. Dhaliwal LK, Das I, Gopalan S. Recurrent leiomyoma of the vagina. Int J Gynaecol Obstet. 1992 Apr;37(4):281-3. doi:10.1016/0020-7292(92)90330-L PubMed PMID: 1350544. 